\title{
ANALISIS VALUE ENGINEERING UNTUK EFISIENSI BIAYA (STUDI KASUS: PROYEK APARTEMEN YUKATA SUITES ALAM SUTERA TANGERANG)
}

\author{
1) Gabriel Kusumo Hendrianto, Prodi Teknik Sipil, Universitas Sebelas Maret \\ 2) Ir. Sugiyarto, M.T., Prodi Teknik Sipil, Universitas Sebelas Maret \\ 3) Ir. Ary Setyawan, M.Sc., Ph.D., Prodi Teknik Sipil, Universitas Sebelas Maret \\ Jl. Ir. Sutami 36A, Surakarta 57126; Telp. 0271-634524. Email: gabrielkusumo@gmail.com
}

\begin{abstract}
$V$ alue Engineering is application of value methodology in a project or services that have been planned or conceptualized to achieve value enhancement. The aims of this study are to find out the type of work that can be streamlined by VE method and how much influence of VE tow ards the cost of construction projects. VE analysis performed in construction project Yukata Suites Apartment Alam Sutera, Tangerang.

Stages of VE study known as V alue engineering job plan are divided into five stages. Those are information, creative, analysis, development and recommendation stage. First stage, Information stage is collecting as much data about project to be analyzed. The second stage is creative, stage that containing suggested alternatives. Third one is analysis stage that contains cost calculation and the analysis of work component's functions. Fourth stage is development stage where the final alternatives are being presented along with the possibility for being implemented. Final stage is presentation to convince the decision-makers about things that already developed by VE's study team.

The project cost that already planned before analysis is Rp. 280.500.000.000,00 and the project cost after VE analysis has been done reduced into Rp. 278.207.577.133,72. The VE analysis give impact in cost saving with amount Rp. 2.084.020.787,53. The best suggested alternatives are the use of precast stairs and dimension reduction in column structure.
\end{abstract}

Key words: value engineering, structure, precast, column.

\begin{abstract}
Abstrak
$V$ alue engineering (VE) adalah aplikasi metodologi nilai (value methodology) pada sebuah proyek atau layanan yang telah direncanakan atau dikonsepkan untuk mencapai peningkatan nilai (value).Tujuan dari penelitian ini adalah untuk mengetahui jenis pekerjaan yang dapat diefisiensikan dengan metode VE dan seberapa besar pengaruh VE terhadap biaya proyek konstruksi. Analisis VE dilakukan pada proyek pembangunan Apartemen Yukata Suites Alam Sutera Tangerang.

Tahapan studi VE dikenal dengan istilah value engineering job plan yang dibagi menjadi lima tahap, yaitu tahap informasi, kreatif, analisis, pengembangan dan rekomendasi. Tahap pertama yaitu tahap informasi yaitu mengumpulkan sebanyak mungkin data mengenai proyek yang akan dianalisis. Tahap kedua adalah kreatif adalah tahapan yang berisi alternatif-alternatif yang disarankan. Tahap ketiga analisis yaitu tahap yang berisi perhitungan biaya dan analisis fungsi komponen pekerjaan tersebut. Tahap keempat yaitu tahap pengembangan yaitu tahap dimana alternative disajikan secara final dan kemungkinanannya untuk di implementasikan. Tahapan terkahir yaitu presentasi adalah tahap untuk meyakinkan kepada para pengambil keputusan tentang apa yang sudah dikembangkan oleh tim studi VE.

Pengaruh dari analisis VE yang telah dilakukan yaitu mendapatkan cost saving pada pekerjaan struktur sebesar Rp. 2.084.020.787,53. Biaya proyek yang telah direncanakan sebelumnya sebesar Rp. 280.500.000.000,00 dan biaya proyek setelah dilakukan analisis VE sebesar Rp. 278.207.577.133,72. Alternatif terbaik yang disarankan adalah penggunaan tangga pracetak dan pengurangan dimensi pada struktur kolom.
\end{abstract}

Kata kunci: value engineering, struktur, precast, kolom.

\section{PENDAHULUAN}

Seiring dengan berjalannya waktu, pertumbuhan penduduk di Indonesia juga semakin meningkat membuat kebutuhan manusia akan ruang semakin bertambah seiring dengan meningkatnya aktivitas bisnis dalam masyarakat. Kurangnya lahan pada daerah perkotaan membuat pembangunan arah vertikal menjadi suatu pilihan yang pas untuk memenuhi kebutuhan saat ini. Pembangunan arah vertikal ini meliputi berbagai jenis bangunan baik untuk rumah tinggal (rumah susun, apartement, condominium hote), perkantoran, pertokoan, hotel dan sebagainya. Upaya pembangunan apartemen ini sebagai salah satu solusi untuk menampung masyarakat yang kesulitan dalam mendapatkan tempat tinggal tetap. Dengan banyaknya pembangunan yang ada, dibutuhkan perencanaan konstruksi yang efisien dan optimal agar tepat sasaran dalam memenuhi kebutuhan yang ada.

Value Engineering (VE) merupakan sebuah kreatif, pendekatan yang teroganisir yang sasarannya adalah untuk mengoptimalkan biaya atau kinerja dari sebuah fasilitas atau system (Dell'Isola, 1974). Pendekatan yang digunakan diarahkan ke analisis fungsi. Apabila tidak mempunyai sifat-sifat menguntungkan untuk keperluan tersebut, biaya tersebut dikeluarkan tanpa mengurangi mutu dan tetap menjaga lingkungan serta mengutamakan keselamatan (Dell'Isola, 1974). VE digunakan untuk mencari suatu alternatif-alternatif atau ide-ide yang bertujuan untuk menghasilkan biaya yang lebih baik/lebih rendah dari harga yang telah direncanakan sebelumnya dengan batasan 
fungsional dan mutu pekerjaan (Dell'Isola, 1974). Selain itu, VE juga dapat digunakan untuk meningkatkan kinerja, kualitas, dan life cycle cost. Dalam perencanaan VE biasanya melibatkan pemilik proyek, perencana, para ahli yang berpengalaman dibidangnya masing-masing, dan konsultan VE (LEED Green Associate Study Guide, 2011).

Studi kasus pada penelitian VE ini adalah pada Proyek Pembangunan Apartemen Yukata Suites Alam Sutra Tangerang. Apartemen ini terdiri dari 34 lantai dan tiga basement dengan nilai kontrak sebesar Rp. 225.000.000.000,00. Pekerjaan struktur pada proyek ini memiliki biaya dan bobot yang paling besar. Desain kolom yang ada pada proyek apartemen ini dirasa boros dan kurang efisien. Dengan dilakukannya penelitian analisis VE pada proyek tersebut diharapkan akan memperoleh suatu nilai yang efisien sehingga didapat penghematan biaya pada pekerjaan struktur.

\section{LANDASAN TEORI \\ Dasar Teori \\ Value Engineering}

VE adalah aplikasi metodologi nilai (value methodology) pada sebuah proyek atau layanan yang telah direncanakan atau dikonsepkan untuk mencapai peningkatan nilai (value). Metodologi nilai adalah sebuah proses sistematis yang digunakan oleh disiplin untuk meningkatkan nilai dari sebuah proyek melalui analisis terhadap fungsi-fungsinya (standar SAVE, 2007).

VE adalah suatu sistem pemecahan masalah yang dilaksanakan menggunakan kumpulan teknik tertentu, ilmu pengetahuan, tim ahli, pendekatan yang kreatif dan terorganisir yang bertujuan untuk mendefinisikan dan menghilangkan biaya yang tidak diperlukan seperti biaya yang tidak memberikan konstruksi bagi mutu, kegunaan, umur, dan penampilan produk serta daya Tarik konsumen (Miles, 1972).

\section{Sejarah VE}

VE mulai dikembangkan pada Perang Dunia ke-2 sekitar tahun 1939-1945. Pada saat itu perusahaan General Electric yang tengah mempersiapkan perlengkapan persenjataan mengalami kesulitan karena meningkatnya kebutuhan persenjataan yang demikian pesat. Sebaliknya perusahaan mengalami kesulitan menghadapi kekurangan kebutuhan material untuk memproduksi perlengkapan persenjataan tersebut, serta mengalami kekurangan terhadap kebutuhan tenaga kerja. Untuk menghadapi kesulitan tersebut, Purchasing Engineer perusaahaan General Electric bernama Lawrence Miles mengembangkan suatu alternatif solusi dan diaplikasikan pada bidang produktivitas untuk mencapai skedul yang diperlukan. Lawrence Miles menemukan cara dengan penggantian material yang dipergunakan ini, akan memberikan penampilan yang sama bahkan lebih baik, namun dengan biaya yang lebih rendah. "Pendekatan Fungsi" ini menjadi kunci keberhasilannya yang kemudian menjadi dasar Value Engineering \& Analysis Techniques (Suriana, 2014).

\section{Perkembangan VE di Indonesia}

VE mulai diperkenalkan pada tahun 1986 oleh Suriana Chandra melalui seminar-seminar yang diadakan di berbagai kota. Pada tahun yang sama metode ini digunakan pada Proyek Pembangunan Jalan Layang Cawang. Pada tahun 1987 Badan Perencanaan Pembangunan Nasional (Bappenas), Departemen Keuangan, dan Direktorat Jenderal Cipta Karya menganjurkan pemakaian VE di Indonesia untuk seluruh pembangunan rumah dinas dan gedung negara di atas 1 milyar rupiah.

\section{Struktur Kolom}

Kolom adalah batang tekan vertikal dari rangka struktur yang memikul beban dari balok. Kolom merupakan suatu elemen struktur tekan yang memegang peranan penting dari suatu bangunan, sehingga keruntuhan pada suatu kolom merupakan lokasi kritis yang dapat menyebabkan runtuhnya (collapse) lantai yang bersangkutan dan juga runtuh total (total collapse) seluruh struktur (Sudarmoko, 1996). SK SNI T-15-1991-03 mendefinisikan kolom adalah komponen struktut bangunan yang tugas utamanya menyangga beban aksial tekan vertikal dengan bagian tinggi yang tidak ditopang paling tidak tiga kali dimensi lateral terkecil. Fungsi kolom adalah sebagai penerus beban seluruh bangunan ke pondasi. Bila diumpamakan, kolom itu seperti rangka tubuh manusia yang memastikan sebuah bangunan berdiri. Kolom termasuk struktur utama untuk meneruskan berat bangunan dan beban lain seperti beban hidup (manusia dan barang-barang), serta beban hembusan angin.

\section{Struktur Tangga}

Tangga adalah bagian dari bangunan bertingkat yang berfungsi untuk penghubung sirkulasi antar lantai bangunan bertingkat dengan berjalan naik atau turun menggunakan trap (anak tangga). Secara umum dan biasa dikenal, tangga 
terdiri dari dua jenis yaitu tangga utama dan tangga darurat. Sesuai namanya, tangga utama merupakan lintasan yang dilalui setiap saat. Sebaliknya tangga darurat dilalui pada saat tertentu.

\section{METODE PENELITIAN}

Penelitian ini mengangkat disiplin ilmu manajemen konstruksi dengan menggunakan analisis Value Engineering Job Plan terhadap proyek pembangunan Apartemen Yukata Alam Sutra Tangerang. Metode merupakan langkah kerja yang memudahkan suatu pelaksanaan kegiatan dalam mencapai suatu tujuan tertentu. Metode penelitian dalam penyusunan skripsi ini meliputi metode pengumpulan data primer dan data sekunder, metode analisis dan prosedur penelitian. Data yang digunakan dalam penelitian ini yaitu Rencana Anggaran Biaya (RAB), gambar kerja, harga satuan pekerjaan, bahan, material dan tenaga kerja. Metode analisis yang digunakan pada penelitian ini adalah analisis Value Engineering Job Plan dengan lima tahapan yaitu tahap informasi, tahap kreatif, tahap analisis, tahap pengembangan dan tahap presentasi.

\section{Tahap Informasi}

Tahap ini merupakan tahap awal studi VE yang bertujuan untuk memperoleh suatu pengertian secara menyeluruh terhadap sistem, struktur, atau bagian-bagian yang dilakukan studinya. Dalam menentukan sasaran studi, dilakukan analisis hukum pareto terhadap biaya proyek dan dilakukan pemahaman terhadap kriteria pembangunan apartemen sehingga diketahui pekerjaan yang akan dianalisis menggunakan VE.

\section{Tahap Kreatif}

Tahap kreatif value engineering job plan merupakan tahap untuk menghasilkan berbagai macam alternatif yang dapat memenuhi atau menjalankan fungsi utama. Pada tahap ini dikembangkan ide-ide guna memperbanyak alternatif yang akan dipilih dengan brainstorming.

\section{Tahap Analisis}

Tahapan dari VE ini bertujuan untuk mengevaluasi alternatif-alternatif yang dihasilkan dalam tahap keatif. Hasil dari evaluasi ini dipergunakan untuk menentukan alternatif yang bermanfaat untuk dilakukan studi lebih lanjut yang akan memberikan potensi terbesar penghematan biaya.

\section{Tahap Pengembangan}

Tahap pengembangan objektif value engineering job plan adalah mempersiapkan saran-saran (rekomendasi) final secara tertulis untuk alternatif yang terpilih. Kemungkinan untuk diimplementasikan, termasuk pertimbangan faktorfaktor teknis dan ekonomis yang mana alternatif tersebut telah secara lengkap dikembangkan untuk memungkinkan diimplementasikan.

\section{Tahap Presentasi}

Tahap presentasi objektif value engineering job plan adalah untuk meyakinkan kepada para pengambil keputusan tentang apa yang telah dikembangkan secara lengkap oleh tim studi dan direkomendasikan pada tahap presentasi ini.

\section{HASIL DAN PEMBAHASAN}

\section{Tahap Informasi}

Berikut ini adalah hasil dari analisis grafik pareto dan breakdown cost model pada proyek Apartemen Yukata Suites Alam Sutera, diperoleh pekerjaan dengan bobot terbesar adalah pekerjaan struktur.

Tabel 1. Hasil Breakdown Cost Model

\begin{tabular}{ccccc}
\hline No & Uraian Pekerjaan & Biaya (Rp.) & Persentase Biaya (\%) & Persentase Kumulatif (\%) \\
\hline 1 & Struktur & $95.406 .579 .308,42$ & 37,41 & 37,41 \\
\hline 2 & Arsitektur & $78.583 .442 .063,62$ & 30,82 & 68,23 \\
\hline 3 & M\&E & $45.000 .000 .000,00$ & 17,65 & 85,88 \\
\hline 4 & Persiapan & $25.602 .625 .587,84$ & 10,04 & 95,92 \\
\hline 5 & Plumbing & $10.005 .235 .000,00$ & 3,92 & 99,84 \\
\hline 6 & Additional Item & $402.118 .040,12$ & 0,16 & 100,00 \\
\hline \multicolumn{7}{c}{ Total } & $255.000 .000 .000,00$ & & \\
\hline
\end{tabular}

Tabel 1 menjelaskan hasil analisis breakdown cost model yang telah dilakukan. Didapatkan pekerjaan bobot terbesar yaitu pekerjaan struktur dengan persentase $37,41 \%$. 


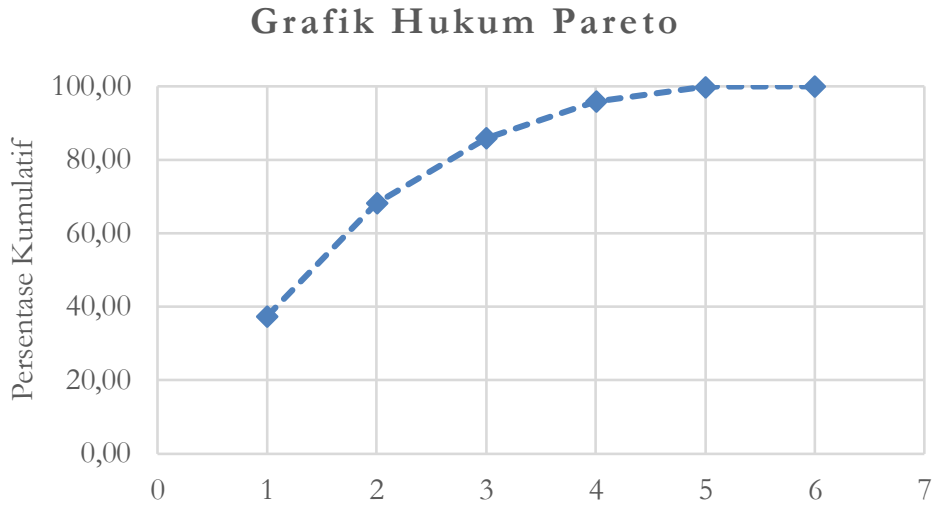

Gambar 1. Grafik Analisis Hukum Pareto Biaya Keseluruhan Proyek

Grafik 1 menunjukkan hasil analisis hukum pareto pada proyek Apartemen Yukata Suites Alam Sutera. Pekerjaan layak untuk dianalisis lebih lanjut karena dalam grafik pareto memeliki persentase lebih besar dari 20\% pekerjaan seluruhnya.

\section{Tahap Kreatif}

Dengan pertimbangan yang didasari dari hasil analisis hukum pareto, maka studi VE yang dilakukan pada penelitian ini akan difokuskan pada pekerjaan beton yang memiliki bobot pekerjaan besar. Analisis ini dimaksudkan untuk mencari item-item pekerjaan proyek yang sekiranya cukup signifikan untuk dianalisa dengan metode VE. Akan tetapi karena keterbatasan data dan informasi yang diperoleh, maka studi VE hanya dilakukan pada dua item berbobot potensial yaitu pekerjaan tangga dan pekerjaan kolom. Adapun alternatif yang diajukan sebagai pengganti yaitu pada pekerjaan tangga adalah penggunaan beton precast dan pengurangan dimensi pada kolom.

\section{Tahap Analisis}

Tahap Analisa merupakan tahap mengevaluasi, menganalisis dan mengkritik pada masing-masing alternatif yang diperoleh dari tahap kreatif. Hasil dari evaluasi ini dipergunakan untuk menentukan apakah alternatif tersebut bermanfaat untuk diterapkan. Berikut merupakan hasil perhitungan biaya eksisting dan alternatif yang disarankan.

Tabel 2. Rekapitulasi Biaya Pekerjaan Tangga Eksisting

\begin{tabular}{cccccc}
\hline No & Uraian Pekerjaan & Volume & Satuan & Harga Satuan (Rp.) & Jumlah Harga (Rp.) \\
\hline 1 & Beton Tangga Fc' 29,05 Mpa & 229,35 & $\mathrm{M}^{3}$ & $887.679,00$ & $203.589 .178,65$ \\
\hline 2 & Bekisting Tangga & $1.609,37$ & $\mathrm{M}^{2}$ & $140.040,00$ & $225.376 .174,80$ \\
\hline 3 & Tulangan Besi Beton & $46.912,2$ & $\mathrm{Kg}$ & $8.876,00$ & $416.391 .089,52$ \\
\hline \multicolumn{7}{c}{ Total Biaya } \\
\hline
\end{tabular}

Tabel 2 menunjukkan rekapitulasi biaya pekerjaan tangga eksisting pada proyek Apartemen Yukata Suites dengan biaya sebesar Rp. 845.356.442,97.

Tabel 3. Rekapitulasi Biaya Pekerjaan Tangga Precast

\begin{tabular}{cccccc}
\hline No. & Uraian Pekerjaan & Volume & Satuan & Harga Satuan (Rp.) & Jumlah Harga (Rp.) \\
\hline 1 & Beton Tangga Fc' 29,05 Mpa & 229,35 & $\mathrm{M}^{3}$ & $887.679,00$ & $203.589 .178,65$ \\
\hline 2 & Bekisting Precast & & & & \\
\hline Fabrikasi Bekisting & $1.609,37$ & $\mathrm{~m}^{2}$ & $97.000,00$ & $156.108 .890,00$ \\
\hline Biaya Fabrikasi Bekisting & 1,0000 & $\mathrm{~m}^{3}$ & $9.700,00$ & $9.700,00$ \\
\hline Upah Setting & 1,0000 & $\mathrm{~m}^{3}$ & $17.500,00$ & $17.500,00$ \\
\hline 3 & Minyak Bekisting & 0,5000 & $\mathrm{ltr}$ & $13.026,00$ & $6.513,00$ \\
\hline Tulangan Besi Beton & $46.912,2$ & $\mathrm{Kg}$ & $8.876,00$ & $416.391 .089,52$ \\
\hline Total Biaya & & & & $776.122 .871,17$ \\
\hline
\end{tabular}


Tabel 3 menunjukkan rekapitulasi biaya pekerjaan tangga alternatif dengan menggunakan precast. Adapun biaya yang diperoleh sebesar Rp. 776.112.871,17.

Tabel 4. Rekapitulasi Biaya Pekerjaan Kolom Eksisting

\begin{tabular}{|c|c|c|c|c|c|}
\hline No & Uraian Pekerjaan & Volume & Satuan & Harga Satuan (Rp.) & Jumlah Harga (Rp.) \\
\hline 1 & $\begin{array}{c}\text { Pekerjaan Kolom Fc' 33,2 } \\
\text { Mpa }\end{array}$ & 1595,41 & $\mathrm{M}^{3}$ & $945.298,00$ & $1.508 .139 .016,54$ \\
\hline 2 & $\begin{array}{c}\text { Pekerjaan Kolom Fc' 41,5 } \\
\mathrm{Mpa}\end{array}$ & 2239,81 & $\mathrm{M}^{3}$ & $1.003 .493,00$ & 2.247.630.244,45 \\
\hline 3 & Pekerjaan Bekisting Kolom & 18176,33 & $\mathrm{M}^{3}$ & $135.750,00$ & $2.467 .436 .667,18$ \\
\hline 4 & $\begin{array}{l}\text { Pekerjaan Tulangan Besi } \\
\text { Beton Kolom }\end{array}$ & 1103104,86 & $\mathrm{Kg}$ & 8876,00 & $9.791 .158 .740,46$ \\
\hline \multicolumn{5}{|c|}{ Total Biaya } & 16.014.364.668,64 \\
\hline
\end{tabular}

Tabel 4 menunjukkan perhitungan rekapitulasi biaya pekerjaan kolom eksisting. Biaya untuk pekerjaan kolom eksisting sebesar Rp. 16.014.364.668,64.

Tabel 5. Rekapitulasi Biaya Pekerjaan Kolom Alternatif

\begin{tabular}{cccccc}
\hline No & Uraian Pekerjaan & Volume & Satuan & Harga Satuan (Rp.) & Jumlah Harga (Rp.) \\
\hline 1 & $\begin{array}{c}\text { Pekerjaan Kolom Fc' 33,2 } \\
\text { Mpa }\end{array}$ & 394,31 & $\mathrm{M}^{3}$ & $945.298,00$ & $372.742 .344,98$ \\
\hline 2 & $\begin{array}{c}\text { Pekerjaan Kolom Fc' 41,5 } \\
\text { Mpa }\end{array}$ & 2175,04 & $\mathrm{M}^{3}$ & $1.003 .493,00$ & $2.182 .641 .428,69$ \\
\hline 3 & Pekerjaan Bekisting Kolom & 12177 & $\mathrm{M}^{3}$ & $135.750,00$ & $1.653 .027 .346,61$ \\
\hline 4 & $\begin{array}{c}\text { Pekerjaan Tulangan Besi } \\
\text { Beton Kolom }\end{array}$ & 1103104,86 & $\mathrm{Kg}$ & 8876,00 & $9.791 .158 .740,46$ \\
\hline \multicolumn{6}{c}{ Total Biaya } \\
\hline
\end{tabular}

Tabel 5 menunjukkan perhitungan rekapitulasi biaya pekerjaan kolom alternatif dengan pengurangan dimensi. Adapun biaya yang diperoleh untuk pekerjaan altenatif kolom sebesar Rp. 13.999.569.857,64.

\section{Tahap Pengembangan}

Dengan melihat hasil analisis maka pada tahap ini direkomendasikan pekerjaan kolom alternatif dengan pengurangan pada dimensinya serta penggunaan tangga precast dikarenakan biaya yang dikeluarkan lebih murah dengan kekuatan struktur yang masih aman.

\section{Tahap Presentasi}

Biaya pekerjaan kolom eksisting adalah sebesar Rp. 16.014.367.073,37 dan biaya pekerjaan tangga eksisting (konvensional) sebesar Rp. 845.356.442,97. Setelah dilakukan analisis dan perhitungan struktur, maka desain alternatif yang disarankan adalah penggantian dimensi kolom dan penggunaan tangga pracetak. Untuk pekerjaan kolom diperoleh penghematan Rp. 2.014.797.215,73 atau 12,58\% dan untuk pekerjaan tangga sebesar Rp. 69.223.571,80 atau $8,19 \%$. Berikut adalah perbandingan biaya eksisting dan setelah dilakukan analisis VE.

Tabel 6. Rekapitulasi Hasil Akhir Penghematan Biaya

\begin{tabular}{|c|c|c|c|c|c|}
\hline No & Uraian & Biaya Existing (Rp.) & Biaya Alternatif (Rp.) & Selisih (Rp.) & $\%$ \\
\hline 1 & Pekerjaan Kolom & $16.014 .367 .073,37$ & $13.999 .569 .857,64$ & 2.014.797.215,73 & 12,58 \\
\hline 2 & Pekerjaan Tangga & $845.356 .442,97$ & $776.122 .871,17$ & $69.223 .571,80$ & 8,19 \\
\hline
\end{tabular}

Dari tabel 6 dapat diketahui besar penghematan untuk alternatif pekerjaan yang telah diberikan. Untuk pekerjaan kolom diperoleh penghematan sebesar 12,58\% dan untuk pekerjaan tangga diperoleh penghematan sebesar 8,19\%.

\section{SIMPULAN}

Jenis pekerjaan yang diefisiensikan dengan metode VE adalah pekerjaan kolom dengan alternatif pengurangan dimensi dan pekerjaan tangga dengan alternatif penggunaan tangga pracetak. Pengaruh dari analisis VE yang telah dilakukan yaitu mendapatkan cost saving pada pekerjaan struktur sebesar Rp. 2.084.020.787,53 dengan rincian peker- 
jaan kolom memperoleh penghematan sebesar Rp. 2.014.797.215,73 atau 12,58\% dan pekerjaan tangga memperoleh penghematan sebesar Rp. 69.223.571,80 atau 8,19\%. Biaya proyek yang telah direncanakan sebelumnya sebesar Rp. 280.500.000.000,00 dan biaya proyek setelah dilakukan analisis VE sebesar Rp. 278.207.577.133,72.

\section{REKOMENDASI}

1. Setelah dilakukan analisis VE, maka direkomendasikan pekerjaan kolom dengan alternatif dimensi dan penggunaan tangga pracetak agar diperoleh efisiensi biaya.

2. Pada penelitian selanjutnya sebaiknya juga diteliti mengenai aplikasi VE untuk tenaga kerja dan waktu pelaksanaan proyek.

3. Penerapan VE tidak hanya dapat dilakukan pada pekerjaan struktur (pekerjaan dengan presentase biaya besar), tetapi juga dapat dilakukan untuk pekerjaan lainnya yang memiliki potensi penghematan seperti arsitektur, mekanikal dan elektrikal serta plumbing.

4. Untuk mendapatkan penghematan yang optimal, VE dapat dilibatkan pada setiap tahapan proyek, mulai dari tahap konsep, perencanaan dan pelaksanaan. Hal ini terutama dapat dilaksanakan pada proyek yang besar dengan jumlah item pekerjaan yang banyak.

\section{UCAPAN TERIMAKASIH}

Ucapan terima kasih pertama ditujukan kepada Tuhan YME atas limpahan rahmat dan nikmatnya. Selanjutnya kepada Ir. Sugiyarto, M.T. dan Ir. Ary Setyawan, M.Sc., Ph.D. selaku dosen pembimbing yang telah memberi arahan dan masukan dalam penelitian ini.

\section{REFERENSI}

Afandi Ari Ahmad, Optimasi pemanfaatan jalan Margonda Raya Depok dengan metode value engineering. Skripsi Fakultas Teknik Universitas Indonesia.

Anisa Wahyu Tri Utami. 2013. Aplikasi value engineering dengan metode analytical hierarchy process terhadap struktur pelat pada proyek pembangunan Hotel Aziza Solo. Skripsi Fakultas Teknik Universitas Sebelas Maret.

Anonim. LEED® Green Associate Study Guide. 2011.

Anonim. Society of American Value Engineering. 2007.

Dell, Isola, Alphonse. 1974. Value Engineering in the Construction Industry. New York: Construction Publishing Corp., Inc.

Dell, Isola, Alphonse. 2008. Value Engineerinb: Practical Application for Design Construction Maintanance \& Operations. Kingston: RS Means Company.

Diyar Rahma. 2016. Analisis value engineering dengan metode zero-one pada proyek pembangunan gedung laboratorium computer kampus 3 universitas ahmad dahlan Yogyakarta. Skripsi Fakultas Teknik Universitas Sebelas Maret.

Herry Priyanto. 2010. Pengoptimalan penerapan value engineering pada tahap desain bangunan Gedung di Indonesia. Tesis Fakultas Universitas Indonesia.

Hutabarat, J. 1995. Diktat Rekayasa Nilai (V alue Engineering). Malang: Institut Teknologi Nasional.

Miles, Lawrence D. 1972. Techniques of V alue Analysis and Engineering. New York: McGraw-Hill Book Company.

Short, A., Barret P., Dye, A., Sutrisna, M. 2007. Impacts of Value Engineering on Five Capital Arts Projects. Building Research and Information, Vol. 35, (3), pp. 287-315

Sri Puji Lestari. 2011. Penerapan value engineering untuk efisiensi biaya pada proyek bangunan gedung berkonsep green building. Skripsi Fakultas Teknik Universitas Indonesia.

Suriana Chandra. 2014. Maximizing Construction Project and Investment Budget Efficiency with Value Engineering. Jakarta: Gramedia.

Wenny Saputri, Saut Martua Hasiholan Saragih. 2014. Aplikasi Rekayasa Nilai (Studi Kasus: Proyek Jalan Tol Semarang-Solo Ruas Semarang Bawen Sesi Penggaron-Beji). Jurnal Karya Teknik Sipil. 3(3): 674-684.

Zimmerman, Larry. 1982. Value Engineering a Practical Approach and Owners Designers and Contractors. Michigan: Van Nostrand. 